\title{
Intra articular fracture of distal end of radius treated by open reduction and internal fixation with buttress plate-a clinical study
}

\author{
Pavankumar H. Patil ${ }^{1}$, Srinivas Pamarathi ${ }^{2}$
}

\begin{abstract}
${ }^{1}$ Department of Orthopedics, Dr B R Ambedkar Medical College, Kadugondanahalli, Bengaluru, Karnataka, India
${ }^{2}$ Sri Padmavati Medical College for Women, Alipiri Road, Tirupati, Andhra Pradesh, India
\end{abstract}

Received: 03 February 2017

Revised: 20 March 2017

Accepted: 01 April 2017

\author{
*Correspondence: \\ Dr. Pavankumar H. Patil, \\ E-mail: drpavanortho@gmail.com
}

Copyright: () the author(s), publisher and licensee Medip Academy. This is an open-access article distributed under the terms of the Creative Commons Attribution Non-Commercial License, which permits unrestricted non-commercial use, distribution, and reproduction in any medium, provided the original work is properly cited.

\begin{abstract}
Background: Recognition of fracture patterns and fixation of fracture to secure and maintain reduction is the key for successful management of more complex intra articular fractures of distal radius. Devices like buttress plates have been shown to provide excellent stability for an unstable fracture with either dorsal or volar metaphyseal comminution. The objective of the study was to evaluate the functional outcome of intra articular fracture of distal end of radius treated by open reduction and internal fixation by buttress plate using Criteria of Gartland and Werley Point System.

Methods: Twenty patients with intra articular fracture of distal end radius were treated by open reduction and internal fixation by buttress plate in Al-Ameen medical college, Bijapur. Statistical analysis: The data obtained was represented as percentage.

Results: The study included 20 patients, 11 males and 9 females aged from 21 to 69 years with mean of 40.2 years. The average duration of follow-up was 7 months ranged from 6-10 months. Using the Demerit scoring system of Gartland and Werley, we had 20\% excellent results, $45 \%$ good results, $20 \%$ fair results and $15 \%$ poor result whereas, excellent to good results were found in $65 \%$ of patients.

Conclusions: Open reduction and internal fixation by buttress plate provides better functional outcome in treating the intra articualar fracture of distal end radius. Excellent to good results are produced by using buttress plate for fixation of intra articular fractures of distal end radius. So, this procedure can be used as alternative to other procedures in treating intra articular fractures of distal end radius.
\end{abstract}

Keywords: Distal end radius, Intra articular fracture, Open reduction internal fixation, Buttress plate

\section{INTRODUCTION}

Fractures of the distal radius have been associated with colorful history since its first description by Ponteau in 1783 and later by Abraham Colle's in $1814 .^{1}$ Previously it was considered as dislocation of wrist. Fractures of the distal end of the radius continue to pose a therapeutic challenge. Some of these fractures are caused by high energy trauma, resulting in intra-articular involvement and comminution. These injuries account for approximately one sixth of all fractures treated in emergency room. ${ }^{2}$

Restoration of radial length, radial tilt angle and congruity of articular surface is important for good functional result. ${ }^{3}$ Failure to achieve and maintain near anatomic reduction can lead to degenerative arthritis, distal radio-ulnar and metacarpal instability and ulnar 
impaction syndrome with resultant pain, decreased mobility, strength and function. ${ }^{4}$ Number of classification system has evolved taking into consideration the fracture patterns, degree of commination, radial shortening and displacement, dorso-palmar displacement, angulations and soft tissue involvement. ${ }^{5}$ This places burden on the surgeon to evaluate each fracture individually.

Open reduction and internal fixation is indicated to address the unstable distal radius fractures and those with articular incongruity that cannot be anatomically reduced and maintained through external manipulation and ligamentotaxis, provided sufficient bone stock is present to permit early range of motion. ${ }^{6}$

Since loss of reduction with subluxation of the carpus is so common, frequently used is a small buttress plate, as described by Ellis, as fixation for volar marginal fractures. ${ }^{7}$ The purpose of this study was to evaluate the functional outcome of surgical management of intra articular fractures of distal radius by open reduction and internal fixation with buttress plate.

\section{METHODS}

This prospective and retrospective study was carried out on 20 patients of revision total hip arthroplasty arthroplasty operated in the tertiary care hospital, Balaji Institute of Surgery, Research and Rehabilitation for the Disabled (BIRRD) Tirumala Tirupati Devasthanams, Tirupati, Andhra Pradesh. This work was carried out between March 2014 to January 2016. Information on the patients was compiled from clinical details, case files and operation theatre records. Patient follow up was done for a minimum of 6 weeks to maximum of 24 months.

The patients who are reporting the outpatient department of our tertiary care hospital, with fracture at distal end of radius classifiable on the Frykman classification system were recruited for the study. Cases were selected on the basis of clinical signs and symptoms, radiological findings confirming intra articular fracture of distal end radius, Frykman classification. Patients who are medically fit and willing for surgery belong to the age group of 20-70 years of both sexes. Patients below the age of 20 years, Patients who are unfit for surgery due to associated medical problems and Patients with pathological fractures were excluded.

Radiographic assessment of wrist (antero-posterior and lateral view) were taken, analysis of the articular involvement and extension of fragments in to diaphysis was done. Patients with intra-articular fractures of distal end of radius were treated by open reduction and internal fixation with buttress plate. Varying pattern of intraarticular fractures of the distal end of radius is common in adults. These injuries are commonly referred as Colle's, Barton's or Smith's fractures, depending on the involvement of the distal radio-ulnar and radio-carpal joint surfaces and the displacement of the fracture fragments. Some of these fractures however are caused by severe trauma, and resulting comminution may defy inclusion in a single eponymous group.

All the patients selected for the study were admitted, examined according to the protocol, associated injuries if any were noted and clinical and laboratory investigations were done in order to get fitness for surgery. Open reduction and internal fixation by buttress plate was done in all patients within 5-7 days of initial trauma. Follow up and assessment at 6 weeks, 3 months, 6 months, final evaluation was performed at 6 months using demeritpoint system of Gartland and Werley. ${ }^{8}$

\section{Surgical approaches and technique}

All the patients underwent open reduction and internal fixation by buttress plate. The aim was to restore the radio-carpal, radio-ulnar joint congruity and to regain radial length. The fractures were approached according to the direction of the displaced fragment. The surgery was carried out under general anesthesia or brachial block after thorough preparation of the parts.

\section{Surgical exposure by volar approach}

In planning the surgical approach, it is important to consider the anatomy of the fracture surface. A longitudinal incision of about $7.5 \mathrm{~cm}$ long was taken on the radio volar aspect. The plane between the flexor carpi radialis and the palmaris longus was developed. The flexor policies longus tendon was retracted radially and the median nerve and the other tendons were retracted towards ulna. The fibers of the pronator quadratus were severed from their origin on the radius and the fracture was exposed. Fracture was reduced and a buttress plate was contoured so that when it is applied and fixed to the proximal fragment, the distal transverse part will act as a buttress and hold the fracture reduced. A minimum of two screws were inserted in the proximal fragment. Whenever possible, screws were inserted through the distal part of the plate into the fracture fragments. The reduction of the fracture and restoration of the articular surface was confirmed by direct observation and by antero-posterior and lateral views in $\mathrm{C}$ arm. Pronator quadratus was placed over the plate to its origin on the radius and wound was closed.

\section{Surgical exposure by dorsal approach}

The dorsal surgical approach is more straightforward, because fewer soft tissue structures need exposure. A longitudinal, midline skin incision provides excellent exposure. The plane of dissection is between the second and third compartment. In a similar manner, the articular fragments can be seen by extension of the approach through the dorsal capsule and fracture exposure is accomplished. Dorsal buttress plate contoured over the distal radius. Reduction checked under image intensifier. A minimum of two screws inserted in the proximal 
fragment. Whenever possible, screws were inserted through the distal part of the plate into the fracture fragments and wound closed in layers.

\section{Post-operative protocol}

After the surgery, the operated limb was supported with an anterior or posterior splint and was kept elevated for 3 days till the edema subsided. All the patients received antibiotics, analgesics and anti-inflammatory drugs to prevent infection and to relieve pain and swelling. Active movements of the fingers, elbow and shoulder were started on the first post-operative day. On the $3^{\text {rd }}$ postoperative day, the operated wound was inspected and active movements of fingers and wrist were encouraged and the range of movements depending upon the tolerance of pain by the patients. As the patient's tolerance to pain increased they were motivated for more vigorous physiotherapy regime. Sutures were removed on $10-12^{\text {th }}$ post-operative day. The splints were discarded and were replaced by a crepe bandage and patients were advised to carryout normal activity within the crepe bandage and resistant major activities. Non-compliant patients were advised to wear the splints till the first follow-up. All the patients were reviewed at the $6^{\text {th }}$ week, $3^{\text {rd }}$ month and $6^{\text {th }}$ month postoperatively and were evaluated clinically and radiologically. Patients were enquired regarding pain, restriction of motion, disability and grip strength. Clinical examination regarding the movements at the wrist and fingers were done. Careful examination was done to rule out any infection.

\section{Statistical analysis}

The data obtained in the present study was reported as percentages.

\section{RESULTS}

Radiological examination consisted of assessing the consolidation of the fracture site, collapse at the fracture site and any displacement of the implant. The final evaluation was done on the $6^{\text {th }}$ month. The patients were evaluated according to standard objective and subjective criteria using demerit-point system of Gartland and Werley. ${ }^{8}$ The longest follow-up in this series was 10 months. The distal end radius fractures were seen more commonly on right side (Table 1). In our study the most common mode of injury causing distal end radius fractures was Road traffic accident (RTA) $40 \%$, followed by fall on outstretched hand with incidence of $30 \%$ (Figure 5).

Frykman type VII fractures of distal end radius was observed more commonly due to RTA mode of injury and Frykman type III fracture of distal end radius was more seen in the fall on outstretched hand. In our study maximum number of cases was of Frykman type III fractures, 8 cases followed by Frykman type VII fractures, 5 cases (Table 2).
Final evaluation in our series was done at 6 months follow up on the basis of demerit point system of Gartland and Werley. ${ }^{8}$ The minimum duration of followup for final evaluation in our series was 6 months. The maximum duration was up to 10 months. In our series 4 patients had excellent results accounting for $20 \%$, 9 patients had good results accounting for $45 \%, 4$ patients have fair results accounting for $20 \%$ and 3 patients had poor results accounting for $15 \%$ (Figure 6). Poor results were seen more in Frykman type VII injury (Table 3).
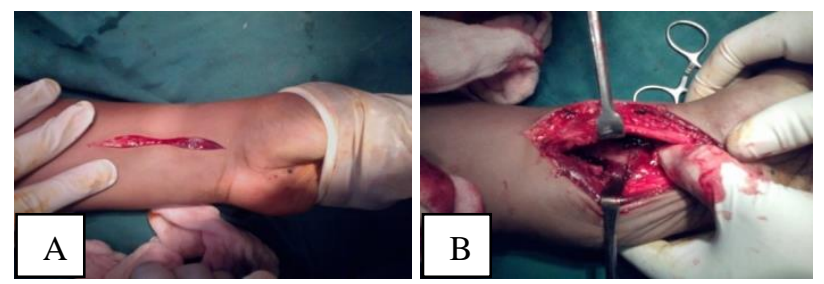

Figure $1 \mathrm{~A}$ and B: Operative photographs.

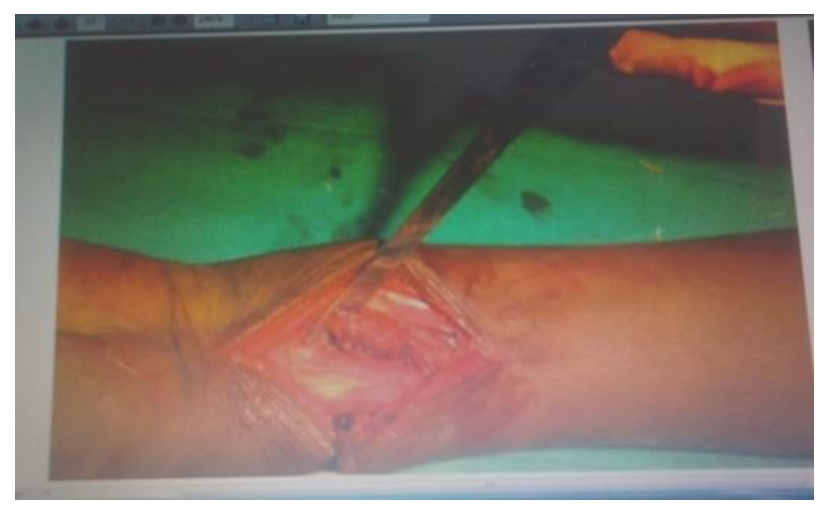

Figure 2: Incision over the volar aspect to expose the fracture site

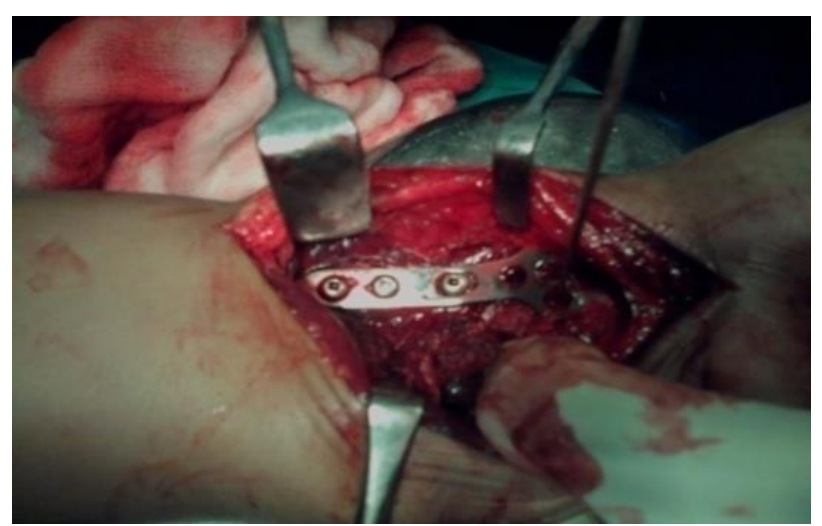

Figure 3: Pronator quadrates cut $\&$ elevated Fracture reduced and buttress plate applied.

Table 1: Percentage of patients based on the side involvement.

\begin{tabular}{|lll|}
\hline Side involved & No of patients & Percentage \\
\hline Right & 14 & 70 \\
\hline Left & 6 & 30 \\
\hline
\end{tabular}




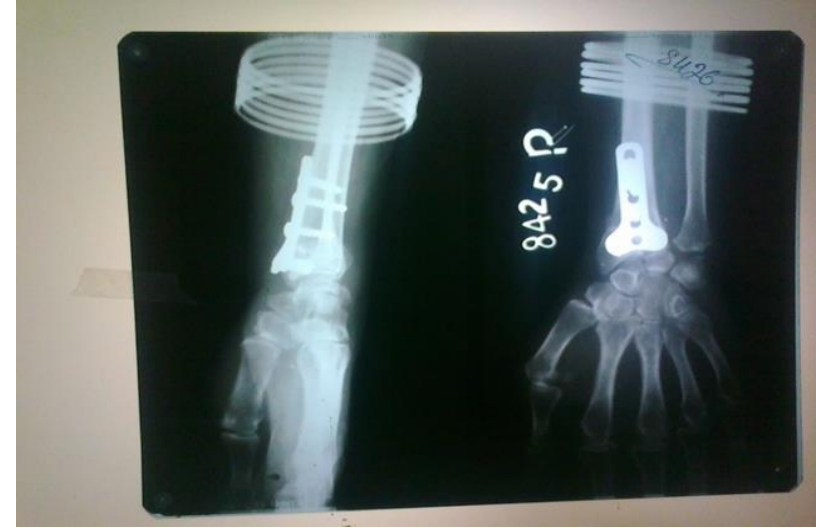

Figure 4: Radiograph showing the right distal radius fracture preoperative.

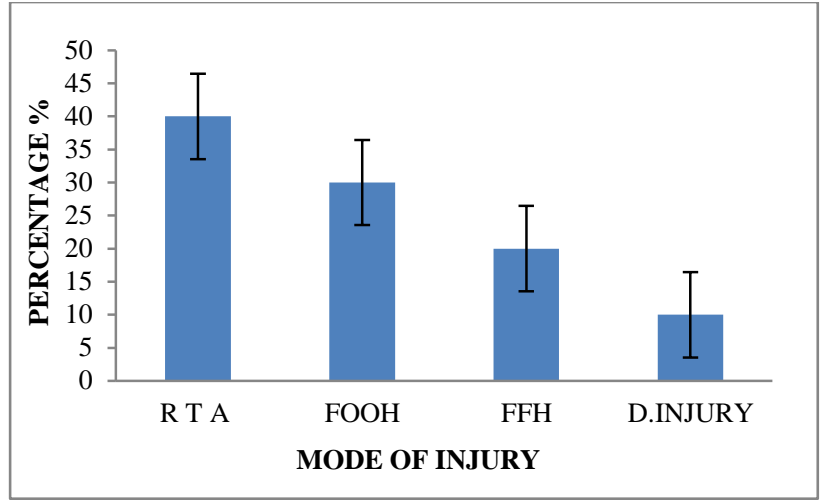

Figure 5: Graph showing mode of injury.

RTA- Road traffic accident, FOOH- Fall on outstretched hand, FFH- Fall from height and D. injury- Direct injury.

Table 2: Percentage of patients based on the Frykman type and mode of injury.

\begin{tabular}{|c|c|c|c|c|c|c|c|c|c|c|}
\hline \multirow{2}{*}{ Mode of injury } & \multicolumn{8}{|c|}{ Frykman type } & \multirow{2}{*}{ Total } & \multirow{2}{*}{$\%$} \\
\hline & I & II & III & IV & V & VI & VII & VIII & & \\
\hline RTA & - & - & 1 & - & 1 & 1 & 4 & 1 & 8 & 40 \\
\hline Fall On Outstretched Hand & - & - & 4 & - & 1 & - & 1 & - & 6 & 30 \\
\hline Fall From Height & - & - & 2 & 1 & 1 & & - & - & 4 & 20 \\
\hline Direct injury & - & - & 1 & - & 1 & - & - & - & 2 & 10 \\
\hline Total & - & & 8 & 1 & 4 & 1 & 5 & 1 & 20 & \\
\hline
\end{tabular}

Table 3: Evaluation of results in Frykman types.

\begin{tabular}{|c|c|c|c|c|c|c|c|c|c|}
\hline \multirow{2}{*}{ Results } & \multicolumn{8}{|c|}{ Frykman type } & \multirow{2}{*}{ Total } \\
\hline & I & II & III & IV & $\mathbf{V}$ & VI & VII & VIII & \\
\hline Excellent & - & - & 3 & - & - & - & 1 & - & 4 \\
\hline Good & - & - & 4 & 1 & 2 & 1 & 1 & - & 9 \\
\hline Fair & - & - & 1 & - & 1 & - & 1 & 1 & 4 \\
\hline Poor & - & - & - & - & 1 & - & 2 & - & 3 \\
\hline
\end{tabular}

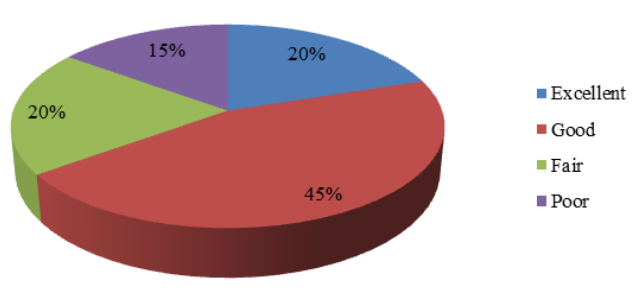

Figure 6: Pie chart showing the percentage of results.

\section{DISCUSSION}

This study was undertaken to assess the functional outcome of operative management of intra articular fracture distal end radius by open reduction and internal fixation by buttress plate.

In the present study, Frykman's classification was used for classification of the fracture type. In this study, buttress plates were used for intra articular fractures of distal end of radius. They were best handled by open reduction and internal fixation by buttress plates. It should be emphasized that these fractures not only have gross displacement of fragments but also have compressed and crushed juxta-articular fragments which is of no supportive value. A buttress purchasing instrument provides a good hold on proximal fragments and lays a very important role by contributing to the stability. In this study 20 patients were treated with buttress plates for intra-articular fractures of distal end of radius, followed up for a minimum of 6 months, were analyzed according to the criteria of demerit point system of Gartland and Werley. ${ }^{8}$ Four patients had excellent results (20\%), 9 patients had good results (45\%), 4 patients had fair results $(20 \%)$ and 3 patients had poor results $(15 \%)$.

According to John K. Bradway and William P Cooney, sixteen patients with comminuted intraarticular fractures of distal radius, with a mean follow up of 5.7 years. ${ }^{9}$ They had 56\% of their patients rated excellent, $25 \%$ good and $19 \%$ fair. This high percentage of excellent and good results compared to our study may be due to fact that the follow up was of longer duration and they had better 
patient's compliance. Bone grafting was done in more number of patients.

In the present study, 11 patients were below the age of 40 years. 3 patients were between $40-50$ years and 2 patients were between 50-60 years and 4 patients were above 60 years. The average age of 20 patients was 40.2 years. In the series of Bradway and Cooney, the average age of the 16 patients were 40 years. ${ }^{9}$ Thus, compared to this series, the average ages of the patients were almost similar and there were high incidence of male patients in our series.

In our study involvement of right side $(70 \%)$ was more than the left (30\%). The right side was dominant for all the patients with right side involvement. This may be due to fact that dominant extremity reaches out first to have first impact of trauma. In our series, the mode of injury in 8 patients were due to RTA (40\%), 6 patients sustained injury due to fall on outstretched hand (30\%), 4 due to fall from height $(20 \%)$ and 2 patients $(10 \%)$ sustained a direct blow.

In the series of Bradway and Cooney, the commonest mechanism was fall on outstretched hand, seen in 11 patients $(69 \%)$ and RTA in 4 patients $(31 \%){ }^{9}$

The final result in our series after an average follow up of 7 months (6-10 months) showed that 4 patients (20\%) had excellent result. Of this 1 patient was above 40 years and 2 were below 30 years and 1 below 40 years. 3 patients had Frykman type III and 1 patient had type VII fractures. 2 patients had their trauma due to RTA, 1 patient had sustained injury due to fall on outstretched hand and 1 patient due to fall from height.

9 patients $(45 \%)$ in our series had good result. 4 patients were below 30 years, 1 patient was below 40 years, 1 patient was below 50 years, 2 patients were below 60 years and 1 patient was above 60 years. Of these 4 patients had Frykman type III injury, 1 had type IV, 2 had type V, 1 had type VI and 1 had type VII injury. The mode of injury in 3 patients were due to RTA, 2 patients had fall on outstretched hand, 2 had injury due to fall from height, and 2 due to direct injury.

4 patients $(20 \%)$ in our series had fair results. 2 patients were over 60 years, 1 patient was below 30 years and 1 patient below 40 years. 2 patients sustained injury due to fall on the outstretched hand, 1 patient sustained injury due to RTA and 1 due to fall from height. 3 patients had poor results in our series (15\%). 1 patient below 40 years, 1 patient below 50 years and 1 patient above 60 years of age. 2 patients had RTA and 1 patient had fall on outstretched hand injury. 1 patient had type 5 and 2 patients had type 7 injury.

Analyzing the results as per the age, revealed that 11 patients $(55 \%)$ were below 40 years of age, of these 3 had excellent result (27.2\%), 5 had good results (45.4\%), 2 had fair and 1 had poor results. 9 patients were above 40 years of age of which 1 had excellent results (11.1\%), 4 had good results $(44.4 \%), 2$ patients had fair results and 2 had poor results. This reveals that younger the patients better are the result. This may be due to better quality of the bone, high motivation to get back pre-injury status and better patient compliance.

In our series of 20 patients bone grafting was done in 3 patients. All of them were over 40 years of age. Of these none had excellent result, 1 had good results, 1 had fair result and 1 had poor result. This shows that the use of bone grafting may not have a bearing on the end result.

\section{CONCLUSION}

Excellent to good results were seen in $65 \%$ of patients by using buttress plate for fixation of intra articular fractures of distal end radius. Thus, open reduction and internal fixation by buttress plate provides better functional results in intra articular fractures of distal end of radius. So, this procedure can be used as alternative to other procedures in treating intra articular fractures of distal end radius. Road traffic accidents and fall on outstretched hand were the commonest mode of injury. Males were affected more than female and younger the patients better the results.

\section{Funding: No funding sources \\ Conflict of interest: None declared \\ Ethical approval: The study was approved by the institutional ethics committee}

\section{REFERENCES}

1. Cooney WP. Fracture of distal radius, a modern treatment based classification. Orthop Clin North Am. 1993;24:211-6.

2. Jakim I, Pieter HS, Sweet MBE. External fixation for intraarticular fractures of distal radius. J Bone Joint Surg (Br).1991;73:302-6.

3. Jupiter JB. Current concepts review fracture of distal end of radius. J Bone Joint Surg (Am). 1991;292:48-61.

4. Richard A, Ro Gachferky MD, Lipson SR. Treatment of severely comminuted intraarticular fracture of distal end of radius by open reduction combined internal and external fixation. $\mathrm{J}$ Bone Joint Surg (Br). 2001;83:215-26.

5. Cooney WP, Linscheid RL, Dobyn JH. External pin fixation for unstable Colle's fracture. J Bone Joint Surg. 1979;61:840-6.

6. Gerostathopoulos Nicolaos, Kalliakmanis Alkiviadis, Fandridis Emmanouil, Georgoulis Stylianos. Trimed Fixation system for Displaced fractures of the Distal Radius. J Trauma. 2007;62(4):913-8.

7. Andrew CH. Fractures of Shoulder, Arm, and Forearm. In: Campbell's operative Orthopaedics. Chapter 54. 10th edition. Philadelphia: Mosby, Inc; 2003: 3058-3066. 
8. John J. Gartland, Charles W. Werley. Evaluation of healed colle's fractures. J Bone Joint Surg Am. 1951;33:895-907.

9. Bradway JK, Amadio PC, Cooney WP III. Open reduction and internal fixation of displaced, Comminuted intra-articular fractures of the distal end of the radius. $\mathrm{J}$ Bone Joint Surg. 1989;71(6):839-47.

Cite this article as: Patil PH, Pamarathi S. Intra articular fracture of distal end of radius treated by open reduction and internal fixation with buttress plate-a clinical study. Int J Res Orthop 2017;3:518-23. 